\title{
A Rational Choice Perspective on "Womenomics" and on the Increasing Phenomenon of Single Women in Japan
}

\author{
Cut Zita Hardilla Putri ${ }^{1}$ and Kurniawaty Iskandar ${ }^{2}$ \\ \{ ${ }^{1}$ zitahp2@gmail.com, ${ }^{2}$ daradwipa@yahoo.com $\}$ \\ ${ }^{1,2}$ School of Strategic and Global Studies, Universitas Indonesia, Indonesia
}

\begin{abstract}
The increasing age of Late married women or choosing unmarried (bankouka) makes serious social problems in Japan. The decline in birth rates contributes to drastic changes in population composition in Japan. There are several factors that cause unmarried women in Japan, such as education, good careers, and government policy towards women in Japan.The womenomics policy in Japan as an effort to create gender equality through education and the world of work for women has created a dilemma. On the one hand women are required to be an intellectual but patriarchal system that restricts, encouraging Japanese women to demand freedom. This study analyzes higher education as a rational choice for Japanese women in realizing womenomics policies. While women's opportunities in the public sector are inversely proportional to their role in the domestic sector. This research uses qualitative method by using the result of secondary data in journal.The results of the analysis of this study indicate that higher education strongly affects the decision of women in choosing to delay even the decision not to marry at all.
\end{abstract}

Keywords: Late marriage, higher education, social change, Womenomics, rational choice theory

\section{INTRODUCTION}

Most of the men in Japan entered into matrimony in the 1980s. Over time, however, the incidence of Japanese men choosing to remain single increased and certain factors that occurred between 2000 and 2010, have caused this rate to grow for Japanese women as well.

Education is one of the abovementioned factors. In Japan, marital relations are strongly influenced by education. In general, a person who has a tertiary degree is expected to hold a steady and substantial employment with a well-respected income. Conversely, those who are not very educated tend to be linked to low incomes.

Up to the late 1980s, the institution of marriage was not a specific matter of concern in Japan. A change occurred in 1989, when the level of fertility in Japan dropped surprisingly and dramatically. The phenomenon became known as the "1.57 shock" and referenced the rapid decrease in fertility rates to less than two births per woman. (Seike, 2016) 
After World War II, Japan witnessed a decline in the rate of childbirth and this condition was named Shousika, the standard word for expressing low birth rates and problems that were occurring in Japan. Shousika may be attributed to two factors: late marriage, defined as the act of entering into matrimony after age 50; and people choosing not to marry.

In 1980, the average age of first marriage was 25.11 years for women and 28.67 years for men. By 2005, this statistic had changed to 29.42 years for women and 31.14 years for men. (Nozaki and Matsuura, 2010), evidencing that both men and women increasingly preferred to remain single for longer.

The results related to changes in the age of marriage in Japan as collated from a 2009 Demographic Statistics Data Book survey, the National Institute of Population, and the Social Security Research elucidate that in 1980 , only $2.10 \%$ of Japanese men remained at age 28.0. For women aged 25.0 years, the rate of remaining single in 1980 was $4.30 \%$. In $1985,3.00 \%$ of Japanese men were still unmarried men at age 30.0 while the percentage of unmarried women at age 26.0 was computed as 4.10 .

In 1990, 5.80\% of Japanese men were never married even age 31.0; for women aged 27.0, the percentage of singlehood declined slightly at 4.0. Five years later, $6.0 \%$ of Japanese men were still single at the same age of 31.0; this rate echoed with women, $5.80 \%$ of whom stayed single at age 28.0. In 2000, the numbers of unmarried Japanese continued to swell in both men and women: $12.0 \%$ of the men were still single at 40.0 years old is and $6.0 \%$ of Japanese women were unmarried at 30.0 years. By 2005, 16.0\% of the men were bachelors at 48.0 years and there was a sharp increase in the number of unmarried women aged 33.0 years: $8.0 \%$. According to Nozaki and Matsuura (2010), Japan's statistics for unmarried citizens are high in comparison to the data available from other developed countries such as Britain, France, and Germany.

Socioeconomic forces encompass all the factors related to the satisfaction of the needs of a community. These aspects include clothing, food, housing, education, health, and other social and fiscal systems, events, occurrences, values, and experiences. According to research conducted by Melly (1975), an individual's socioeconomic status may be noted through employment, income earned, and education. On this basis, an individual may be classified into low, medium, and high socioeconomic positions within a particular community. These socioeconomic realities, including the control of adequate income to meet one's needs, exert a strong impact on the happiness of women in Japan (Koentjaraningrat, 1981:35).

Socioeconomics is important to marriage as an institution. The Ministry of Health, Labor and Welfare also conducts a regular survey on poverty levels in people aged 20-64 years based on their marital status and sex. In 1995, poverty caused $14.1 \%$ of Japanese men to stay unmarried and in 2007, this rate increased to $18.0 \%$. Likewise, poverty was cited as the cause of the increase in the numbers of unmarried Japanese women, $13.9 \%$ of whom remained single in 1995; their percentage has continued to increase and were estimated to reach $16.5 \%$ in 2007 (Nozaki and Matsuura, 2010). Thus, fiscal aspects have great bargaining power on the institution of marriage, and it is proven that economic problems are one of the causes of the delayed age for marriage in the Japanese people, regardless of their gender.

The figures quoted above evidence the social shift in the condition of marriage in Japan from 1960 to 2005 and elucidate the consistent increase in the age of marriage for men and women. 


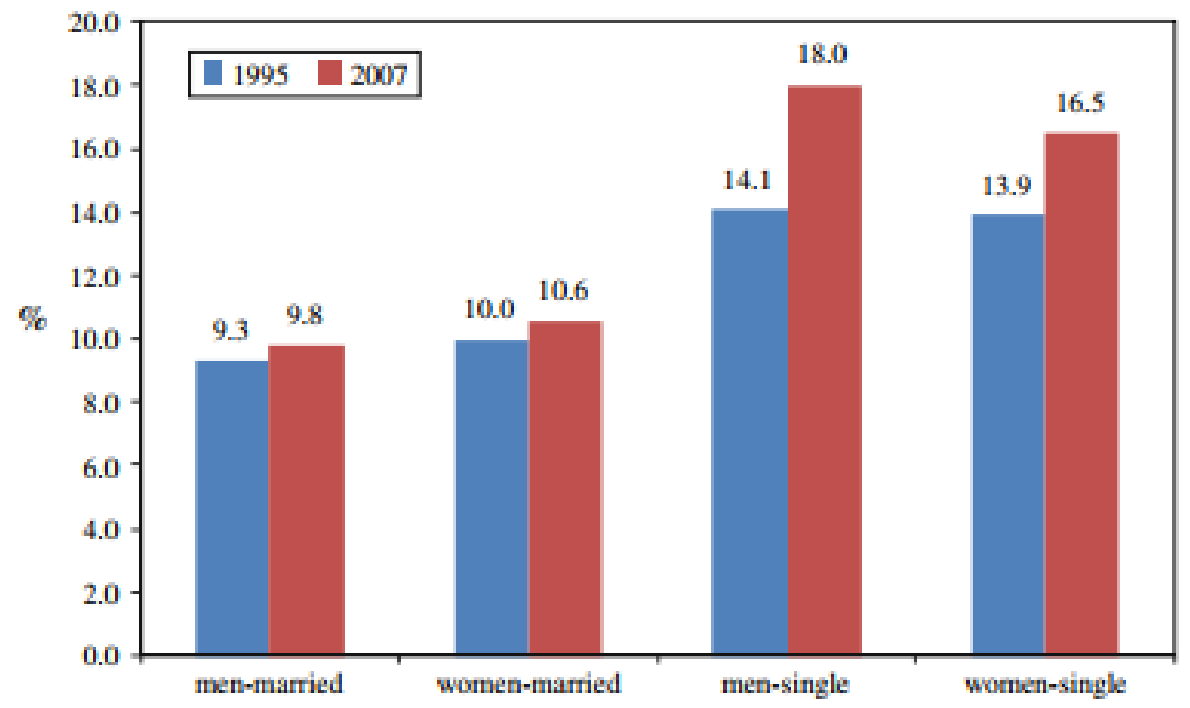

Figure 1. Poverty level based on marital status and sex: ages 20-64 years

In their article on marriage and happiness in Japan and in the United States, Kaufman and Taniguchi (2010) claim that marriage represents an intimate relationship and yields a positive attitude that enhances a sense of harmony and happiness for a couple that enters into the bonds of matrimony. In contrast, those who are not married or who choose not to marry are considered likely to feel the negative effects of their decision to remain single such as rumors, gossip, pejorative nicknames, or loneliness in old age. The authors also cite Evan and Kelley's (2004) study of life satisfaction in the United States. This investigation found that men and women feel greater life satisfaction after marriage. Numerous previous studies have found positive associations between marriage and happiness. Nobe (1999) asserted that family ties, including those of marriage, are closely knit in Japan and they exert great influence on the happiness of Japanese women. Those who subscribe to the principle of marriage tend to value happiness and to ensure the bond of marriage yields happiness to all beings associated with it. This is especially true for women (Kaufman and Taniguchi, 2010).

The present study will continue on the path of the abovementioned previous studies and will delve deeper into the causative factors responsible for the increasing trend of women choosing to remain unmarried in Japan. Baik itu dari sisi pendidikan, sosial, kebudayaan dan ekonomi. Karena jika dilihat dengan kacamata gender, tidak ada salahnya seorang wanita memiliki pendidikan yang tinggi dan mandiri secara finansial. Therefore, the present investigation will focus on the internal and external reasons for the increasingly delayed ages for first time marriages in Japan for both genders and on the role of higher education as part of Japan's Womenomics policies being a rational choice for Japanese women not to get married in a hurry. 


\section{LITERATURE REVIEW}

According to K. Sato, Mitsuyo Suzuki, and Michi Kawamura (1987), compulsory education and equal opportunity policies led to augmented levels of women's education in Japan. The results of their research revealed that in 1979, only $12.2 \%$ of Japanese women graduating from high school progressed to university and that only $20.9 \%$ of these women continued toward a second (D-2) or advanced degree. This percentage has continued to grow for women entering university either for two or four years.

The number of women in tertiary education has shown a surprising increase year after year even though the subjects of study offered to women are quite limited. At universities, many women choose to major in the humanities and education disciplines, and many female D-2 students choose home economics, education, and humanities. Women's universities comprise 93.3\% of the home economics majors offered in Japan. They also primarily offer arts, humanities, and education majors. In contrast, women's universities account for only $10 \%$ of all engineering and social sciences departments. However, the number of women in the social science disciplines has increased slightly since the 1960 s.

In $1979,72.3 \%$ of the women who graduated from D-2 and $62.9 \%$ of the women graduating from universities found work. These job placement rates increased further between 1964 and 1974. Economic growth and industrialization also boomed after the war in Japan and this situation also made a large impact on women's economic activities.

The shifts in the marital status of female employees must also be considered at this juncture. In 1969, women who were single worked, but married women traditionally became home-makers according to the prevalent values of the times. Circumstances turned in 1979 when $67.0 \%$ of the married, widowed, or divorced women entered the workforce in some capacity. Women's views on marriage have changed since 1972. In 1969, 8\% of the 32\% female respondents surveyed considered "a woman should be married because the happiness of a woman depends on being married." Conversely, in 1972, 23\% of the women surveyed believed that "marriage is not a necessity if a woman is able to support herself."

The traditional Japanese family system has political and communal import by virtue of the society's harmony, its solidarity, and its loyalty to the state and to Confucian teachings. In traditional Japanese families, the lineage is more important than the marriage of two individuals. The family line is drawn from the ancestors of the parents to the eldest sons as their heirs. Marriage occurs to keep the heir at home or within the family i.e., The ideal Japanese family has three generations living under one roof. The changes occurring in the family structure in the present are usually attributed to women who are married and who also want to perform productive work outside the household. Currently, women are unemployed only because they do not want to work, or because they cannot find a job, or because they are waiting to find their aspirational employment.

However, the gap in wages for men and women remains and should be eliminated. Better education, good positions at work, and also expanding employment opportunities for women can help to narrow the wage gap. Japanese women are encouraged now more than ever before to prove their self-esteem by earning their fiscal independence and promoting their economic achievements.

Over the past thirty years, the decline in Japanese birth rates has been very striking and it has become a national concern with fertility rates well below the population replacement rate (Faruqee and Mühleisen, 2001). This decline was caused by two directly related factors: the decrease of marriage rates (Sakamoto and Kitamura, 2008) and by the increase in the average age of first marriages. 
At the end of her research career, Edwards (2015) believed that the decline in birth and marriage rates in Japan over three decades was influenced by Japan's Equal Employment Opportunity Act (EEOA) of 1985. Although the rise is not simultaneous, a woman's decision to choose to continue her education and to choose to marry grows together. The Japanese EEOA and the expanding availability of career opportunities for university-educated women were factors that contributed to the decline of the institution of marriage in Japan in the last 30 years.

Indonesia is a country concerned with varied aspects such as technology, economics, economics, and education. However, without education, all these aspects will not flourish in the manner in which they currently are. Education is a conscious learning process that generates behavior changes in a person through a group (Edwards, 2015). Linda N. Edwards' (1988) ideas support Brown (1961), who concluded that education is a learning process that begins at birth and lasts throughout life. This conscious understanding suggests a level of awareness of the goals to be achieved. Education is also for a means for all nations to advance, because it holds the key to the progress and success of a country.

Education is a positive gift for the community when it can also shape the ideas of a society and can bring about desired change in a community. Good or bad, changes impact people and filter forward to encompass larger sections of humanity. For instance, bankonka or the phenomenon of delayed marriages for Japanese citizens who choose work too much and who desire personal freedom, is one of negative effects of education that may be observed in Japan. Further, the hikonka experience of the growing numbers of Japanese citizens who choose not to marry may also be cited as detrimental to the social fabric of the Japanese. According to Sumiko Iwao (1996), the tendency of Japanese women to delay marriage is strongly related to their higher education. In other words, the more educated the women become in Japan, the higher the rate of delay in their age of marriage.

According to Keiko Fujiwara (1988), in modern times the education of Japanese women began to be promoted more than a hundred years ago at the beginning of the Meiji era (18681912). The education imparted in the Meiji era defined the ideal image of Japanese women within the family and in society. Fujiwara (1988) claims that in feudal times before the Meiji period, women were destined only to serve and to obey men. They were required to be gentle in attitude, courteous, kind, and submissive. Their position within the community was repressed and even oppressed. The 1946 Constitution clearly prohibits discrimination on the basis of sex and for the first time, women were given the right to speak out in public and they could begin to pursue social equality. The circumstances are currently certainly better for women in terms of equality in education and career opportunities, but there still remains a serious gap between the sexes in terms of nominal and substantial profits. Women's rights are still not completely recognized in real, social terms.

In 1985, the government enacted the Equal Employment Opportunity Law (EEOL) that mandated parity of employment for men and women. This law came into force in April 1986. It prohibits gender discrimination in vocational training, benefits, pensions, and bars the unjust termination of employment. It also urges companies to try to equalize opportunities for women and men in job recruitment, job assignments, and promotion promotions. (Edwards, 1988)

Many companies began offering jobs to female university graduates after EEOL was established. Women were also allowed to become permanent employees of companies. The percentage of women entering university is thus increasing every year. At the same time, women who continue their tertiary education continue to face comments and opinions that are obliquely negative. However, higher education has also exerted a positive impact in Japanese 
women in the form of increasing their sense of independence, freedom, economic autonomy, confidence, and authority.

Japan revived its economy through industry in the 1960s. Japan's economy continued to grow exponentially until the 1980s. This period of drastic increase is known as the time of the bubble economy when many companies needed labor, and especially hired female workers. As opportunities for women grew, many women continued their education to higher levels. In Fujimura-Fanselow's book (1995), Tanaka stated that education is important in determining the quality of human resources in industrial societies. Economic and social gains are related to the results of the level of education achieved by the workforce. In brief, the higher a person's educational background, the greater the salary earned or in Japanese terms, kogakureki = kochingin. The term kogakureki (educational background) was first used in Japan in 1887 for prospective civil servants. According to Iwata Ryuushi (1988), Japanese-style gakureki emerged because of the prevailing view of the existence and ability of certain people to make judgments because of personal skills and because of the nature of the existing competition. This gakureki of the desired education is expected by the Japanese-style management structure from its human resources.

\section{METHODOLOGY}

The qualitative approach and literature study method was utilized for this research endeavor. According to Creswell (2016), research methods using qualitative approaches serve varied purposes. First, theory is often used in qualitative research to explain certain behaviors and attitudes. Second, the qualitative approach is often used in theoretical perspectives (perspective theory or perspective in qualitative research) to guide research on gender, class, and race. In the 1980s, qualitative research underwent a transformation marked by the emergence of theoretical perspectives to expand the scope of research and to guide researchers in examining issues or problems that were to be studied. The qualitative approach with a theoretical perspective (theoretical lens or perspective in qualitative research) is used for the present investigation to evince the manner in which the studied authors position themselves in the case being considered in this research paper (for example, being on the neutral side without leaning toward or against the aspects that are being investigated, i.e., not taking sides with or against women who choose not to marry or are not married).

\section{ANALYSIS}

Japan is a developed country, but the role of women in the fields of education, politics, economics, and industry is still relatively subdued in comparison to other developed countries. However, Prime Minister Shinzo Abe's economic policy, popularly known as Abenomics, explicitly states the intent of women occupying 30\% of Japan's leadership positions by 2020 as one of its objectives (Sekiguchi, 2014).

When viewed from a demographic point of view, Japan is home to an elderly population and has the most aged workers in the world. Additionally, the country's labor needs are very high according to the Ministry of Internal Affairs and Communications and the Ministry of Health, Labor and Welfare. The extraordinary number of workers above the average age may be the result of the low percentage of women engaged in the industrial sector.

Female workers willing to undergo the same conditions as male corporate soldiers known as sogo shoku (all round employees) are required to be willing to work overtime and to be 
placed in offices that are far from their homes for several years according to their tenure (tanshin funin). They must also be willing to continue to work without interruption, even when they are in the second phase of child rearing.

The primary focus of the Japanese government under Shinzo Abe is to encourage an increase in the level of participation of women as labor because compared to men, the engagement of women as part of the labor force is very low in Japan. This deficiency in participation occurs because women cannot yet be optimally integrated in the implementation of country's development even though they have enormous potential to contribute if they are given the opportunity to be more actively involved. In fact, many Japanese women are highly educated and thus their capabilities may be equal to the men's, but their promise is suppressed by various obstacles that limit the possibility of their participation in the nation's progress.

In 2012 Prime Minister Shinzo Abe issued many policies and one among them aimed at rejuvenating Japan's economic power. Japan experienced a stagnation in 2010 that was equivalent to its plight in 1995. Abenomics, a package of sustainable economic policies to revive the Japanese economy, underscores Shinzo Abe's belief in his policy to encourage women's participation in labor in the country. The policy may say to be inspired by Womenomics, an idea popularized by a 1996 report from Goldman Sachs which states essentially that women perform an important and integral role in the process of the long-term economic development of the State. The Womenomics policy is also known in Japan as the policy on equality of work for women. The term Womenomics was coined by Kathy Matsui in 1999 and Japanese Prime Minister Shinzo Abe acknowledged in September 2013 in the Wall Street journal that Womenomics was not a new concept. He iterated, however, that his government's commitment to pursuing it in Japan was new. Abe also promised to create a society where "all women can shine" (subete no josei ga kagayaku nihon e).

In May 2014, Kathy Matsui estimated in a journal article that the employment rate of women would be aligned to the level of male employment and could increase Japan's GDP by almost $13 \%$. In addition, she also asserted that bridging the gender gap in Japan would improve the performance of companies. Many observers are of the same opinion as Matsui: the long-term demographic problems facing Japan may be overcome if the gender divide is eliminated. The Diplomat reports that Japan's population has declined since 2006 and that it is expected to drop drastically further from the current 127 million to 87 million by $2060.40 \%$ of the population of 87 million people that will remain will be over the age of 65 . Demographic surveys conducted in Japan evidence that the country's population has declined partly because Japanese women choose to delay marriage or to remain single, especially in metropolitan centers such as Tokyo. The average age of marriage among Japanese women is 29 years, and nearly one third of those in their early 30s are unmarried. In comparison, the average age of first marriage for women in the United States is 26.5 (D'Vera et al., 2011).

In some ways, Japan's foundation for bringing more women into the public sector is strong. The country's constitution (drafted by the United States during the post-war Japanese occupation) includes a non-discrimination law and Japan has a robust and progressive legal framework that can support and advance further gender equality goals. At 87 years, Japanese women also have the longest life expectancy in the world; once in the workforce, they can potentially conduct a long and productive career. On the other hand, some analysts have expressed concerns about possible challenges that could limit the success of such "women's" initiatives, especially those related to work culture and to the political climate of Japan.

As a concept, Womenomics illustrates that the increase or reinstatement of women into the public sector or the workforce will increase the power of the economy of the state. Women in 
the world of work represent and actualize gender equality and justice and progress results from efforts to achieve equity and harmony.

Japan's policy of Womenomics was adopted because of the acute decrease in the number of much needed workers to fuel the country's economy, and because the Japanese economy also declined in tandem with the deficiency of the workforce. As reported above, Abe's statement about his government's commitment to pursuing the existing concept of Womenomics being "new" can be interpreted that this policy is aimed at the construction of a new Japan to prevail over a demographic crisis.

Contrarily, women who wish to remain single are generally blamed for the demographic crisis facing Japan. If this is true, how can a policy that tries to attract more women to the formal workforce assist in surmounting the problem of declining birth rates? Given the opportunity to work full time in equal conditions as men, would enough women still be willing to marry, procreate, and stay home to raise children?

Apart from the pressing need for women workers and the dramatic decline in birth rates, two rules that were implemented have made it easier for women to enter the public domain: the Equal Opportunity Law of 1985, and the Child-care Leave Law of April 1992. According to Yoshio (2002), these two legal provisions represent the beginning of efforts to increase the role of women in the workforce by seeking gender equity and the right for women to demand equal opportunities in the public sector.

It is possible to deduce that the government would like women to marry and to have children and to still be able to work. However, government policies provide child day care at extremely high prices that actually make women more desperate. The Japan Times reported the story of a 32-year-old woman who had just received a letter of rejection from Meguro Ward for her 3-month-old son. Meguro Ward is a child day care center funded by the city government. Initially, the woman thought it would not be difficult to avail of childcare. However, finding a daycare proved almost impossible. Several other daycare centers are funded by the government, but the centers have 100 names on average on waiting lists. Working women would ordinarily require spending 150,000 Yen (about 20 million rupiah) per month on private child care. The woman in question was reported as saying that this amount was "too expensive for my salary" and that she "was beyond despair." Despite Womenomics, thus, women have to struggle to earn enough to bear the cost of rearing children. Hence, many independent working women decide not to marry or bear children.

Trading Economics elucidates that the percentage of unemployment in Japan touched 5.6\%, the highest of two decades, between 2008 and 2010. However, after Womenomics was introduced and disseminated, there was a sustainable decline in unemployment and in 2015, Japan's unemployment rate was $3.1 \%$. Thus, Womenomics has been able to usher a positive shift and to affect labor at least twice in recent years. It has also proved capable of improving Japan's domestic sector economy by around $0.9 \%$ since 2014 , boding well for the growth of Japan's national income.

Nevertheless, the concept of ryosaikenbo, the main objective of the creation of education opportunities for women, remains patriarchal. The reality of the collision of concepts espoused by government policies and the values enshrined by Japanese culture give birth to a dilemma for women. Cultural and social constructions that make women the main players of the ryosaikenbo culture become an obstacle to the process of achieving the Womenomics target. Traditional Japanese culture mandates that women are only intended to serve society as good mothers and wives, taking care of the responsibilities of rearing children and managing household affairs. This dominant view is a vital challenge to the policy of Womenomics. 
Two global approaches may be identified as the basis of the contention that a growing number of women join the workforce because of higher educational attainments. The first calculates the greater workability of women as a function of the knowledge and skills transmitted by higher education and their contribution to the development of labor. The second approach investigates the use of higher education credentials by employers to identify the potential of individual, social, and cultural capital (Brennan, 2008; Brown, 2016). Whatever approach is used, higher education is universally believed to influence the willingness and ability of women to enter the labor market because such an action increases their income potential, gives them the mandate needed for work, and changes their attitude toward the traditional role of women in the household and at work (Ahituv and Lerman, 2007; Benavot, 1989; Bianchi, 2011; Carnoy, 2006; Carnoy et al. 2012; Crompton et al., 2007).

Most married women, however, stop working for employment related reasons. The company environment where they work comprises numerous people who harass women workers. Sometimes, this aggravation becomes so severe in the corporate environment that women choose not to marry or delay marriage. One such action is matahara (abbreviated form of Maternity Harassment), a name given to the physical and mental persecution faced by women at their workplaces when they become pregnant, give birth, or raise children. Matahara is considered to be one of the major forms of workplace bullying against women workers.

Alternatively, women often lose their jobs when they find out that they are pregnant. One woman told the New York Times, "I told my boss that I was pregnant and wanted to take time off for medical examinations. When I returned from the hospital, I was fired ... my boss just left a message, saying that I didn't have to bother -reporting to work again. “

Women who choose careers are mostly single, and do not desire to bear children. Some women decide to terminate pregnancies because they do not want to lose their jobs. Matahara is also the result of the awareness of gender discrimination in terms of work. Japan's deepseated cultural values require men to work outside and women to work inside the home, conceptually creating a neat division of the roles and responsibilities of husbands and wives.

The results of a 2015 survey conducted by the Japanese Trade Union Confederation revealed that one in five female workers $(20.9 \%)$ experienced a sun. Sun is the risk of miscarriage and of premature birth. Losses caused by sun are more dangerous than sexual harassment. However, there are no laws yet to handle the problem of sun. The establishment of laws to protect women from sun and the development of measures to prevent instances of sun have become important problems for Japan.

The corporate environment responsible for the sun often applies overtime or encourages more than the usual hours of work (38\%). Around $6 \%$ of companies require workers to put in overtime until midnight. In sum, then, $44 \%$ of Japanese companies guilty of sun keep employees back for extended work hours. Ironically, the employees are not even paid in full every year for the overtime they put in; they merely receive bonuses that are not commensurate with the effort they expend (22\%). In addition, women who take maternity leave are only paid $20 \%$ of their salary. Thus, their annual pay is reduced to around $42 \%$ of their regular salary. This system of long working hours extending till midnight has long been rampant in almost all Japanese companies. A widespread awareness of the social gender role division combined with demands of long working hours are unique case models found only in Japan. Nonetheless, the enforcement of long hours of overtime work is often cited by many companies to be the best course of action for the company.

Women in Japan are divided into three groups: married, pregnant, and homemakers. Most women who work prefer not to marry and favor their careers. This state of affairs continues to 
raise the age of first marriage of the women and to lower the rate of childbirth. This action is taken by women because they are aware of sun victims and thus take the decision to remain single. Japanese women should be responsible for raising children, but sun cases make them afraid of becoming pregnant and bearing children.

About $60 \%$ of working women in Japan stop working when they are pregnant with their first child. $43.1 \%$ female permanent workers return to work after taking maternity leave compared to only $4 \%$ contracted women employees. In developed countries, the rise in the number of births is congruent with the rise in the number of women who work. Conversely, the number of births is decreasing in Japan in tandem with sun problems. Women in the United States faced the same challenges around 40 years ago, and women in France remember that such instances happened in the days of their grandmothers.

There are 4 types corporate actions that can cause sun: the imposition of traditional gender-based values; rounding; power harassment; and coercion to resign from the company to perpetuate traditional gender-based values. For example, women may face statements such as "children are the top priority," "your husband's income should be sufficient," "we only worry about your health" followed by the phrase "you should just resign."

Gender-based differentiation is deeply rooted in Japanese companies. Women who are pregnant or who have children are expected to leave their jobs, to stay at home, and to prioritize their families. This type of sun smoothly enforces traditional values on women personnel.

\section{CONCLUSION}

The government offered a gender equality policy to Japanese women so that they could attain education and employment rights equivalent to men. However, the strategy of Womenomics implicitly contradicts to Japan's patriarchal social system. While the authority of Gender-based differentiation is deeply rooted in Japanese companies. Women are expected not to leave their jobs or to stay at home, and prioritize their lives not to families but given theis more dedicated to company that become the real agent who maintain patriarchy as value system.

The government's Womenomics policy is actually aimed at helping the country's beleaguered economy and at the same time, can continue to assist their families. In terms of ground realities, the traditional cultural values strongly attached to Japanese society still serve to hamper the actualization of the government's objectives.

\section{ACKNOLEDGEMENT}

This research based on grant scheme of PITTA (Publikasi International Terindeks untuk Tugas Akhir) or also known as Indexed International Publications for Final Projects toward Universitas Indonesia students. Thank you to Kurniawaty Iskandar as my advisor.

\section{REFERENCES}

[1]. Archer, M. S., \& Jonathan, Q. T. (2001). Rational choice theory: Critical reealism: Intervention. London and New York: Routledge.

[2]. Creswell, J. W. (2016). Research Design: Pendektatan Metode Kualitatif, Kuantitatif dan Campuran. 
[3]. Fanselow, K. F., \& Anne, E. I. (1991). The education of women in Japan. London and New York: Greenwood Press.

[4]. Fukada, S. (2013). The changing role of women's earnings in marriage formation in Japan.

[5]. Hodge, Robert. W, Naohiro Ogawa. (1992). Fertility change in contemporary Japan. Chicago: The University of Chicago Press.

[6]. Kaufman, G., \& Hiromi, T. (2009). Gender and marital happiness in Japan. International Journal of Sociology of the Family, 35, 69-87.

[7]. Kaufman, G., \& Hiromi, T. (2010). Marriage and happiness in Japan and United States. International Journal of Sociology of the Family, 36, 25-48.

[8]. Leedy, P. D., \& Jeanne, E. O. (2010). Practical research: Planning and design. Ninth Edition.

[9]. Nozaki, Y., \& Katsumi M. (2010). The increasingly high sex ratio and lifelong unmarried rate in Japan. Journal of Population Research, 27, 43-57.

[10]. Retherford, R. D., Naohiro, O., \& Rikiya, M. (2001). Late marriage and less marriage in Japan. Population and Development Review, 27, 65-102.

[11]. Sato, K., Mitsuyo, S., \& Michi, K. (1987). The changing status of women in Japan. International Journal of Sociology of the Family, 17, 87-108.

[12]. Sato, Y. (2013). Rational choice theory. Sociopedia.isa. Japan: Tohoku University.

[13]. Somantri, G. R. (2005). Memahami Metode Kualitatif. Makara, Sosial Humaniora, 9.

[14]. Toshiaki, T. (2010). The new paradox for Japanese women: Greater choice, greater inequality. (Mary. E Foster, Penerjemah). Japan: International House of Japan, Inc.

[15]. Yoshida, A. (2017).nmarried women In Japan. London and New York: Routledge. 